\title{
ANALISIS PEMASARAN KAKAO (Theobroma cacao, L) DI KECAMATAN RANTO PEUREULAK KABUPATEN ACEH TIMUR
}

\author{
Supristiwendi ${ }^{1} /$ Khairuddin $^{2}$ \\ ${ }^{1}$ Dosen Prodi Agribisnis Fakultas Pertanian \\ ${ }^{2}$ Alumni Prodi Agribisnis Fakultas Pertanian \\ UNIVERSITAS SAMUDRA
}

\section{RINGKASAN}

Analisis Pemasaran Kakao (Theobroma cacao, L) di Kecamatan Ranto Peureulak Kabupaten Aceh Timur". Tujuan penelitian Untuk mengetahui pola saluran pemasaran, biaya pemasaran dan margin pemasaran serta efisiensi pemasaran kakao Analisis Pemasaran Kakao (Theobroma cacao, L) di Kecamatan Ranto Peureulak Kabupaten Aceh Timur.

Penentuan lokasi penelitian dilakukan di Kecamatan Ranto Peureulak Kabupaten Aceh Timur dilakukan secara purposive (sengaja) dengan pertimbangan bahwa kecamatan tersebut merupakan daerah sentra tanaman kakao. Penelitian ini menggunakan metode survei. Objek penelitian adalah petani dan pedagang biji kakao yang berada di desa-desa sampel di Kecamatan Ranto Peureulak Kabupaten Aceh Timur. Penelitian ini dilaksanakan pada Bulan Januari sampai Februari 2017.

Pengambilan sampel petani kakao dilakukan dengan metode simple random sampling (sampel acak sederhana). Dalam penelitian ini sampel yang digunakan sebanyak $10 \%$ jumlah populasi. Populasi petani kakao di daerah penelitian sebanyak 659 orang. Sedangkan jumlah petani sampel sebanyak 66 orang terdiri dari 27 orang di Desa Bukit Takteh, 17 orang di Desa Bukit Mancang, 12 orang di Desa Nurul A'la dan 10 orang di Desa Ranto I. jumlah populasi dan sampel lembaga pemasaran sebanyak 24 orang terdiri dari 12 orang pedagang pengumpul desa, 6 orang pedagang pengumpul kecamatan, 4 orang pedagang pengumpul kabupaten dan 2 orang pedagang propinsi.

Hasil penelitian pemasaran kakao di Kecamatan Ranto Peureulak pada dasarnya menggunakan 3 (tiga) saluran pemasaran. Total biaya pemasaran kakao pada saluran 1 sebesar Rp.3.525/Kg, saluran 2 sebesar Rp.2.850/Kg dan saluran 3 sebesar Rp.2.400/Kg. Margin pemasaran kakao di Kecamatan Ranto Peureulak rata-rata sebesar Rp. 7.446,97/Kg, saluran 1 sebesar Rp. 8.500/Kg, saluran 2 sebesar Rp. 8.000/Kg dan saluran 3 sebesar Rp. 5.500/Kg. Penerima keuntungan bersih (net margin) pada saluran 1 adalah pedagang desa yaitu sebesar Rp. $1.450 / \mathrm{Kg}$, pada saluran 2 adalah pedagang kabupaten yaitu sebesar Rp. 2.050/Kg dan saluran 3 adalah pedagang propinsi yaitu sebesar Rp. 1.650/Kg kakao. Farmer Share pemasaran kakao di Kecamatan Ranto Peureulak rata-rata sebesar 74,11 \%. Farmer Share pemasaran pada saluran 1 sebesar 70,18 \% dan saluran 2 sebesar 72,41 \% sedangkan Farmer Share pemasaran saluran 3 sebesar 81,03 \%. Efisiensi pemasaran kakao di Kecamatan Ranto Peureulak ratarata sebesar 10,40 \% (Efisien karena $<50 \%$ ). Efisiensi pemasaran pada saluran 1 sebesar 12,37\% dan saluran 2 sebesar 9,83\% sedangkan efisien pemasaran saluran 3 sebesar 8,28\%. Dari sisi efisiensi pemasaran saluran 3 merupakan saluran pemasaran kakao yang paling efisien karena memiliki efisiensi pemasaran paling kecil dibandingkan saluran 1 dan saluran 2.

Kata Kunci: Kakao, biaya, margin, fungsi, pemasaran

\section{Latar Belakang}

Provinsi Aceh merupakan salah satu daerah yang memiliki potensi pengembangan kakao di Indonesia, disisi lain merupakan daerah yang menjanjikan di wilayah Indonesia Barat untuk pengembangan kakao. Salah satu komoditas andalan ekspor sebagai sember penghasil devisa negara dan menjadi sumber 
penghidupan penghasil devisa negara dan menjadi sumber penghidupan masyarakat secara luas adalah kakao. Potensi pengembangan kakao di Indonesia sangat menjanjikan apabila dikelola secara baik mulai dari budidaya, pascapanen, industri pengolahan, pengemasan hingga proses distribusi dan pemasaran.

Kakao merupakan salah satu andalan ekonomi di Kabupaten Aceh Timur disamping komoditi lainnya seperti padi, kelapa, kelapa sawit. Upaya peningkatan ekonomi petani kakao di Kabupaten Aceh Timur telah dilakukan oleh pemerintah dan Lembaga Swadaya Masyarakat melalui kegiatan pendekatan pertanian berkelanjutan yang di dalamnya meliputi berbagai teknik sistem pertanian, seperti tumpang sari (intercropping), penanganan tanaman, dan pascapanen. (AEDFF, 2012:7).

Masalah utama yang sangat penting adalah pemasaran hasil pertanian. Jika pemasaran hasil pertanian tidak berhasil maka semua usaha yang dilakukan sia-sia, dengan kata lain biaya produksi tidak tercukupi. Masalah inilah yang sering dihadapi petani dimana harga hasil pertanian mereka sangat rendah bahkan ditolak di pasar (Daniel, 2002:52).

Kecamatan Ranto Peureulak merupakan salah satu kecamatan yang terdapat di Kabupaten Aceh Timur. Kecamatan Ranto Peureulak merupakan sentra produksi kakao dimana mempunyai perkebunan kakao rakyat dengan luas 1.397 hektar yang tersebar di 9 (sembilan) desa.

Dalam sistem pemasaran biji kakao sering terjadi perbedaan harga di tingkat petani dengan ditingkat pedagang ekspor (eksportir), hal ini terjadi karena mata rantai pemasaran yang dilalui cukup panjang. Keadaan seperti ini menyebabkan biaya pemasaran menjadi beban biaya proses pemasaran yang akhirnya akan mengurangi profit mata rantai pemasaran. Biasanya masing- masing saluran pemasaran memiliki sebaran harga yang berbeda-beda. Untuk mengetahui saluran mana yang dianggap paling baik dapat diketahui dengan cara menghitung jumlah penjualan/pembelian barang pada setiap masing-masing saluran. Tinggi rendahnya harga yang diterima oleh petani erat kaitannya dengan keadaan struktur pasar dan besarnya margin pemasaran, sehingga untuk meningkatkan pemasaran petani kakao dapat dicapai apabila pola saluran pemasaran dan penyebab tingginya margin pemasaran di ketahui.

Berdasarkan uraian pada latar belakang dengan demikian penulis merasa penting untuk meneliti tentang pemasaran kakao di Kecamatan Ranto Peureulak Kabupaten Aceh Timur.

\section{Identifikasi Masalah}

1. Bagaimana pola saluran pemasaran kakao di Kecamatan Ranto Peureulak?

2. Bagaimana fungsi pemasaran yang dilakukan oleh setiap lembaga pemasaran pada setiap saluran pemasaran kakao di Kecamatan Ranto Peureulak?

3. Seberapa besar biaya pemasaran, margin pemasaran, share margin pemasaran dan farmer's share pada masing-masing saluran pemasaran kakao di Kecamatan Ranto Peureulak?

4. Bagaimana tingkat efisiensi pemasaran pada masing-masing saluran pemasaran kakao di Kecamatan Ranto Peureulak?

\section{Tujuan Penelitian}

1. Untuk mengetahui pola saluran pemasaran kakao di Kecamatan Ranto Peureulak.

2. Untuk mengetahui fungsi pemasaran yang dilakukan oleh setiap lembaga pemasaran pada setiap saluran pemasaran kakao di Kecamatan Ranto Peureulak.

3. Untuk mengetahui, biaya pemasaran, margin pemasaran, share margin pemasaran dan farmer's share pada 
masing-masing saluran pemasaran kakao di Kecamatan Ranto Peureulak.

4. Untuk mengetahui tingkat efisiensi pemasaran pada masing-masing saluran pemasaran kakao di Kecamatan Ranto Peureulak

\section{Hipotesis Penelitian}

1. Terdapat beberapa pola saluran pemasaran kakao di Kecamatan Ranto Peureulak.

2. Terdapat pelaksanaan fungsi pemasaran yang dilakukan oleh setiap lembaga pemasaran pada setiap saluran pemasaran kakao di Kecamatan Ranto Peureulak.

3. Terdapat perbedaan biaya pemasaran, margin pemasaran, share margin pemasaran dan farmer's share pada masing-masing saluran pemasaran kakao di Kecamatan Ranto Peureulak.

4. Pemasaran kakao di Kecamatan Ranto Peureulak sudah efisien.

\section{METODOLOGI PENELITIAN}

Metode, Lokasi, Objek, Ruang Lingkup Penelitian

Penelitian ini menggunakan metode survei. Menurut Nazir (2005:271), "Metode survei adalah penyelidikan untuk memperoleh fakta dari gejala-gejala dan mencari keterangan secara faktual baik tentang intitusi sosial, ekonomi atau politik dari suatu kelompok ataupun suatu daerah". Penelitian dilakukan di Kecamatan Ranto Peureulak Kabupaten Aceh Timur. Penentuan lokasi penelitian dilakukan secara purposive (sengaja) dengan pertimbangan bahwa kecamatan tersebut merupakan daerah sentra tanaman kakao. Objek penelitian adalah petani dan pedagang biji kakao yang berada di desa-desa sampel di Kecamatan Ranto Peureulak Kabupaten Aceh Timur.

\section{Populasi dan Sampel Penelitian}

Kecamatan Ranto Peureulak Kabupaten Aceh Timur terdiri dari 23 desa dimana hanya 9 desa yang memiliki usahatani kakao. Dari 9 desa dipilih sebanyak 4 (empat) desa sampel. Penentuan desa sampel dilakukan secara purposive sampling (sengaja) dengan pertimbang keempat desa tersebut memiliki luas lahan tanaman kakao yang lebih luas dari desa-desa lainnya. Desa sampel tersebut yaitu: Desa Bukit Takteh, Desa Bukit Mancang, Desa Nurul A'la dan Desa Ranto I.

Populasi dalam penelitian terdiri dari 2 (dua) kelompok yaitu populasi petani kakao dan populasi pedagang (lembaga pemasaran) kakao. Menurut Nana (2005:5), "Sampel merupakan sebagian dari populasi yang paling tidak mempunyai satu ciri yang sama dengan populasinya untuk mewakili populasi yang ada".

Pengambilan sampel petani kakao dilakukan dengan metode simple random sampling (sampel acak sederhana). Metode sampel acak sederhana adalah teknik penentuan sampel secara acak tanpa mengenal sampel dengan cara diundi dengan mengikutkan semua populasi yang ada untuk dipilih secara acak. Roscoe (1975) yang dikutip Sekaran (2006:46) memberikan acuan umum untuk menentukan ukuran sampel sebaiknya minimal 30 sampel dan untuk populasi yang besar $10 \%$ sampel dianggap memadai untuk penelitian. Dalam penelitian ini sampel yang digunakan sebanyak $10 \%$ jumlah populasi. Untuk lebih jelas jumlah populasi dan sampel petani kakao masing-masing desa sampel dapat dilihat pada tabel III-1 berikut:

Tabel III-1 : Jumlah Populasi dan Sampel Penelitian di Kecamatan Ranto Peureulak Kabupaten Aceh Timur, 2016

\begin{tabular}{|l|l|c|c|}
\hline No & \multicolumn{1}{|c|}{ Desa } & Populasi (Orang) & Sampel (Orang) \\
\hline 1 & Bukit Takteh & 272 & 27 \\
2 & Bukit Mancang & 175 & 17 \\
3 & Nurul A'la & 116 & 12 \\
\hline
\end{tabular}




\begin{tabular}{|l|l|c|c|}
4 & Ranto I & 96 & 10 \\
\hline & Jumlah & 659 & 66 \\
\hline
\end{tabular}

Sumber : Data Sekunder

Dari Tabel III-1 di atas dilihat bahwa jumlah populasi petani kakao di daerah penelitian sebanyak 659 orang. Sedangkan jumlah petani sampel sebanyak 66 orang terdiri dari 27 orang di Desa Bukit Takteh, 17 orang di Desa Bukit Mancang, 12 orang di Desa Nurul A'la dan 10 orang di Desa Ranto I.

Lembaga pemasaran dalam penelitian ini terdiri dari 4 lembaga pemasaran, yaitu pedagang pengumpul desa, pedagang pengumpul kecamatan, pedagang pengumpul kabupaten dan pedagang eksportir. Pengambilan sampel untuk lembaga pemasaran dilakukan dengan metode pengambilan secara sensus (sampel jenuh), pengambilan secara sensus ini disebabkan jumlah populasi lembaga pemasaran di Kecamatan Ranto Peureulak Kabupaten Aceh Timur relatif kecil. Sampel jenuh adalah sensus, dimana semua anggota populasi dijadikan sampel (Sugioyono, 2008:124).

Jumlah populasi dan sampel lembaga pemasaran sebanyak 24 orang terdiri dari 12 orang pedagang pengumpul desa, 6 orang pedagang pengumpul kecamatan, 4 orang pedagang pengumpul kabupaten dan 2 orang pedagang propinsi.

\section{Teknik Pengumpulan Data}

1) Data primer yaitu data yang diperoleh langsung di daerah penelitian yaitu di Kecamatan Ranto Peureulak Kabupaten Aceh Timur. Tehnik pengumpulan data yang dilakukan yaitu:

- Observasi yaitu dengan pengamatan langsung terhadap objek yang akan diteliti dalam penelitian ini adalah petani kakao di daerah penelitian

- Wawancara yaitu mengadakan tanya jawab langsung dengan para petani kakao di daerah penelitian

- Kuisioner yaitu daftar pertanyaan yang disusun sedemikian rupa untuk diisi oleh responden yang dipandu oleh peneliti.

2) Sedangkan data sekunder adalah sumber data yang berasal dari instansi-instansi terkait yang berhubungan dengan penelitian. Bahan kepustakaan yaitu dengan mengumpulkan data berupa teoriteori yang diperoleh dari literatur-literatur yang berhubungan dengan penulisan skripsi ini.

\section{Variabel dan Data Yang Dianalisis}

Variabel dan data untuk menguji kebenaran hipotesis, yang antara lain :
a. Saluran Pemasaran (type)
b. Fungsi Pemasaran
c. Biaya Pemasaran (Rp/Kg)
d. Margin Pemasaran ( $\mathrm{Rp} / \mathrm{Kg}$ )
e. Share Margin (Rp/Kg)
f. Farmer's Share (\%)
g. Efisiensi Pemasaran

Metode Analisis dan Pengujian Hipotesis.

Data yang diperoleh dari lapangan baik data primer maupun data sekunder diolah dengan mentabulasikan dan kemudian dipindahkan ke dalam bentuk tabelaris sesuai dengan kebutuhan analisis.

\section{Margin Pemasaran}

Untuk menghitung margin pemasaran kakao dapat diketahui dengan rumus sebagai berikut (Hudson dalam Alham, 2013:22):

$$
\mathrm{M}=\mathrm{Pr}=\mathrm{Pf} \text { atau } \mathrm{M}_{\mathrm{i}}=\mathrm{C}_{\mathrm{i}}+\eta_{\mathrm{i}}
$$

Dimana:

$\mathrm{M}=$ Margin total pemasaran
setiap saluran pemasaran
$\mathrm{Pr}=$ Harga kakao di tingkat eksportir (Rp/Kg)

$$
\begin{aligned}
& \text { Pf = Harga kakao di tingkat petani } \\
& (\mathrm{Rp} / \mathrm{Kg}) \\
& \mathrm{M}_{\mathrm{i}} \quad=\text { Margin pemasaran pada } \\
& \text { setiap lembaga pemasaran } i \\
& C_{i}=\text { Biaya pemasaran di pasar } i
\end{aligned}
$$




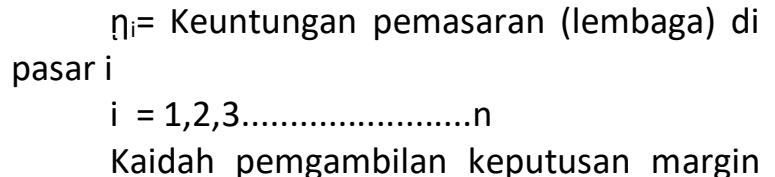
pemasaran ini adalah:

- Jika perbedaan antara harga yang diterima petani dengan harga yang diterima eksportir tinggi maka margin pemasaran tinggi

- Jika perbedaan antara harga yang diterima petani dengan harga yang diterima eksportir rendah maka margin pemasaran rendah

\section{Share Margin Pemasaran}

Untuk menghitung distribusi margin pemasaran tiap lembaga yang terlibat dalam pemasaran cabe digunakan rumus sebagai berikut :

$\begin{array}{lll}\mathrm{SBij} & = & {\left[\mathrm{cij} /\left(\mathrm{P}_{\mathrm{r}}-\mathrm{P}_{\mathrm{f}}\right)\right] \times 100 \%} \\ \mathrm{Cij} & = & \mathrm{Hjj}-\mathrm{Hbj}-\mathrm{lij}\end{array}$

Sedangkan keuntungan lembaga pemasaran kej:
Skj $\quad=\quad\left[\mathrm{Pij} /\left(\mathrm{Pr}_{\mathrm{r}}-\mathrm{P}_{\mathrm{f}}\right) \times 100 \%\right.$
$\mathrm{Pij}=\mathrm{Hjj}-\mathrm{Hbj}-\mathrm{cij}$ (Rahim dan

Retno, 2007:88).

Dimana :

SBij : persentase biaya untuk melaksanakan fungsi pemasaran ke-I oleh lembaga pemasaran ke-j (\%)

Cij : biaya untuk melaksanakan fungsi pemasaran ke-l oleh lembaga pemasaran ke-j (Rp/Kg).

Skj : bagian keuntungan lembaga pemasaran ke-j (\%)

Pij : keuntungan lembaga pemasaran ke-j (\%)

$\operatorname{Pr} \quad$ : harga di tingkat konsumen ( $\mathrm{Rp} / \mathrm{Kg}$ )

Pf : harga di tingkat petani ( $\mathrm{Rp} / \mathrm{Kg}$ )

$\mathrm{Hjj}$ : harga jual lembaga pemasaran ke-j $(\mathrm{Rp} / \mathrm{Kg})$.

$\mathrm{Hbj}$ : harga beli lembaga pemasaran ke-j (Rp/Kg)
Ijj : keuntungan untuk melaksanakan fungsi pemasaran ke-I oleh lembaga pemasaran ke-j (Rp/Kg)

\section{Menghitung Farmer's Share}

Untuk menghitung Farmer's share menggunakan rumus sebagai berikut (Hudson dalam Alham, 2013:22):

FS $\quad=P f / \operatorname{Pr} \times 100 \%$

Diamana;

FS = Bagian harga yang diterima petani $(\%)$

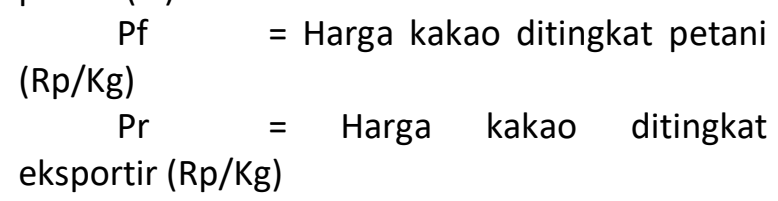

Kaidah pengambilan keputusan farmer's share ini adalah:

- Jika farmer's share adalah < 50\% maka pemasaran tidak memihak kepada petani (belum efisien)

- Jika farmer's share adalah > 50\% maka pemasaran sudah memihak kepada petani (sudah efisien)

\section{Efisiensi Pemasaran}

Efisiensi pemasaran adalah nisbah antara biaya pemasaran total dengan nilai produk yang dijual, dinyatakan dengan persen. Rumus efisiensi pemasaran adalah sebagai berikut:

$$
\text { Ep } \quad=B P / H E \times 100 \%
$$

Dimana:

Ep = Efisiensi pemasaran kakao

$\mathrm{BP}=$ Biaya Pemasaran kakao

$(\mathrm{Rp} / \mathrm{Kg})$

$\mathrm{HE}=$ Harga ditingkat eksportir kakao (Rp/Kg)

Kaidah pengambilan keputusan efisiensi pemasaran ini adalah:

- Jika nilai Ep < 50\% maka saluran pemasaran efisien

- Jika nilai Ep > 50\% maka saluran pemasaran belum efisien 
HASIL DAN PEMBAHASAN

Karakteristik Petani Kakao

Umur rata-rata petani sampel adalah 43,62 tahun, tingkat pendidikan rata-rata adalah 8,68 tahun, pendidikan petani sampel masih rendah, rata-rata pengalaman berusahatani 12,08 tahun dan jumlah tanggungan keluarga rata-rata 5 orang.
Lembaga pemasaran kakao meliputi petani (produsen), pedagang pengumpul tingkat desa, pedagang pengumpul tingkat kecamatan, pedagang pengumpul tingkat kabupaten dan pedagang propinsi. Petani dalam memasarkan biji kakao menggunakan ketiga saluran. Besarnya persentase petani pengguna masing-masing saluran pada pemasaran kakao di Kecamatan Ranto Peureulak dapat dilihat pada Tabel V-2 berikut.

\section{Saluran Pemasaran Kakao}

Tabel V-2. Persentase Penggunaan Saluran Pemasaran yang Dipilih Petani Di Kecamatan Ranto Peureulak, 2016

\begin{tabular}{|c|l|l|l|}
\hline Uraian & Saluran 1 & Saluran 2 & Saluran 3 \\
\hline $\begin{array}{c}\text { Jumlah Lembaga } \\
\begin{array}{c}\text { Pemasaran } \\
\text { Persentase (\%) }\end{array}\end{array}$ & 27 & 19 & 20 \\
\hline
\end{tabular}

Sumber: Data Primer diolah

Tabel V-2 menunjukkan bahwa petani kakao di Kecamatan Ranto Peureulak memilih saluran 1 sebesar 40,91\%, saluran 2 sebanyak $28,79 \%$ dan saluran 3 sebanyak $30,30 \%$. Pemilihan saluran 1 , saluran 2 dan saluran 3 oleh petani kakao mempunyai berbagai pertimbangan meliputi faktor harga, pengangkutan, jarak dan hubungan emosional petani dan pedagang.

\section{Fungsi Pemasaran pada Lembaga Pemasaran Kakao}

Fungsi penjualan yang dilakukan oleh petani dengan menjual kepada pedagang pengumpul desa meliputi pembelian, penjualan dan pengangkutan (transport). Fungsi penjualan yang dilakukan oleh pedagang pengumpul kecamatan dan kabupaten meliputi pembelian, penjualan, pengangkutan (transport), pengemasan dan penyortiran. Fungsi penjualan yang dilakukan oleh pedagang pengumpul propinsi meliputi pembelian, penjualan, pengangkutan (transport), pengemasan, penyortiran, penyimpanan dan penanggungan resiko (penyusutan).

\section{Biaya Pemasaran Kakao}

Biaya pemasaran kakao pada masingmasing saluran pemasaran berbeda karena adanya perbedaan jumlah lembaga pemasaran yang terlibat. Semakin panjang rantai pemasaran maka biaya pemasaran yang tercipta akan semakin besar sebaliknya harga yang diterima produsen akan semakin kecil. Besar kecilnya biaya pemasaran ditentukan oleh seberapa banyak fungsi pemasaran yang dilakukan oleh lembaga pemasaran yang terlibat pada suatu saluran pemasaran. Setiap fungsi pemasaran biasanya diikuti oleh adanya biaya yang dikeluarkan untuk menjalankan fungsi tersebut. Besarnya biaya pemasaran yang ditanggung lembaga pemasaran bisa berbeda walaupun fungsi pemasaran yang dilakukan sama. Semakin panjang saluran pemasaran maka biaya pemasaran juga akan semakin besar. Secara tidak langsung biaya pemasaran dibebankan kepada produsen dengan jalan menerima harga penjualan yang rendah. Biaya pemasaran kakao di Kecamatan Ranto Peureulak yang tercipta pada saluran 1 dapat dilihat pada tabel berikut.

Tabel V-4. Biaya Pemasaran Kakao Pada Saluran 1 Di Kecamatan Ranto Peureulak , 2016 


\begin{tabular}{|c|c|c|}
\hline \multirow[b]{2}{*}{ No } & \multirow[b]{2}{*}{ Lembaga Pemasaran } & \multirow{2}{*}{$\begin{array}{c}\text { Biaya Pemasaran } \\
\text { (Rp/Kg) }\end{array}$} \\
\hline & & \\
\hline 1 & Pedagang Desa & 550 \\
\hline 2 & Pedagang Kecamatan & 775 \\
\hline 3 & Pedagang Kabupaten & 850 \\
\hline 4 & Pedagang Propinsi & 1350 \\
\hline \multicolumn{2}{|c|}{ Total } & 3525 \\
\hline
\end{tabular}

Sumber: Data Primer diolah

Tabel V-4 menjelaskan bahwa total biaya pemasaran kakao pada saluran 1 sebesar Rp.3.525/Kg. Biaya pemasaran yang ditanggung pedagang desa sebesar $\mathrm{Rp} .550 / \mathrm{Kg}$ kakao, pedagang kecamatan menanggung biaya

pemasaran sebesar Rp.775/Kg kakao, pedagang kabupaten menanggung biaya pemasaran sebesar Rp.850/Kg kakao dan pedagang propinsi menanggung biaya pemasaran sebesar Rp.1.350/Kg kakao.

Tabel V-5. Biaya Pemasaran Kakao Pada Saluran 2 Di Kecamatan Ranto Peureulak, 2016

\begin{tabular}{|c|c|c|}
\hline \multirow[b]{2}{*}{ No } & \multirow[b]{2}{*}{ Lembaga Pemasaran } & \multirow{2}{*}{$\begin{array}{c}\text { Biaya Pemasaran } \\
\text { (Rp/Kg) }\end{array}$} \\
\hline & & \\
\hline 1 & Pedagang Desa & 550 \\
\hline 2 & Pedagang Kecamatan & - \\
\hline 3 & Pedagang Kabupaten & 950 \\
\hline 4 & Pedagang Propinsi & 1.350 \\
\hline \multicolumn{2}{|c|}{ Total } & 2.850 \\
\hline
\end{tabular}

Sumber: Data Primer diolah

Tabel V-5 menjelaskan bahwa total biaya pemasaran kakao pada saluran 2 di Kecamatan Ranto Peureulak sebesar Rp.2.850/Kg. Biaya pemasaran yang ditanggung pedagang desa sebesar Rp. 550/Kg kakao, pedagang kabupaten menanggung biaya pemasaran sebesar Rp.
950/Kg kakao dan pedagang propinsi menanggung biaya pemasaran sebesar $\mathrm{Rp}$. 1.350/Kg kakao.

Biaya pemasaran kakao yang tercipta pada saluran 3 di Kecamatan Ranto Peureulak dapat dilihat pada tabel berikut

Tabel V-6. Biaya Pemasaran Kakao Pada Saluran 3 Di Kecamatan Ranto Peureulak, 2016

\begin{tabular}{|l|l|c|}
\hline \multirow{2}{*}{ No } & Lembaga Pemasaran & Biaya Pemasaran \\
\cline { 3 - 3 } & & $(\mathrm{Rp} / \mathrm{Kg})$ \\
\hline 1 & Pedagang Desa & - \\
2 & Pedagang Kecamatan & - \\
3 & Pedagang Kabupaten & 1050 \\
4 & Pedagang Propinsi & 1.350 \\
\hline \multicolumn{2}{|c|}{ Total } & 2.400 \\
\hline
\end{tabular}

Sumber: Data Primer diolah

Tabel V-6 menjelaskan bahwa total biaya pemasaran kakao pada saluran 3 di Kecamatan Ranto Peureulak sebesar Rp.2.400/Kg. Biaya pemasaran yang ditanggung pedagang kabupaten sebesar Rp. 1.050/Kg kakao dan pedagang propinsi menanggung biaya pemasaran sebesar Rp.1.350/Kg kakao. 


\section{Margin Pemasaran Kakao}

Tabel V-7. Margin Pemasaran Kakao Pada 3 Saluran Di Kecamatan Ranto Peureulak, 2016

\begin{tabular}{|l|l|l|l|l|}
\hline N0 & $\begin{array}{c}\text { Saluran } \\
\text { Pemasaran }\end{array}$ & $\begin{array}{c}\text { Harga Petani } \\
(\mathrm{Rp} / \mathrm{Kg})\end{array}$ & $\begin{array}{c}\text { Harga Pedagang Propinsi } \\
(\mathrm{Rp} / \mathrm{Kg})\end{array}$ & Margin $(\mathrm{Rp} / \mathrm{Kg})$ \\
\hline 1 & 1 & $20.000,00$ & $28.500,00$ & $8.500,00$ \\
2 & 2 & $21.000,00$ & $29.000,00$ & $8.000,00$ \\
3 & 3 & $23.500,00$ & $29.000,00$ & $5.500,00$ \\
\hline \multicolumn{2}{|l|}{ Rata-Rata } & $7.446,97$ \\
\hline
\end{tabular}

Sumber: Data Primer diolah

Tabel V-7 menjelaskan bahwa margin pemasaran kakao di Kecamatan Ranto Peureulak rata-rata sebesar Rp. 7.446,97/Kg. Margin pemasaran pada saluran 1 sebesar Rp. 8.500/Kg, saluran 2 sebesar Rp. 8.000/Kg dan margin pemasaran saluran 3 sebesar $\mathrm{Rp}$. $5.500 / \mathrm{Kg}$. Semakin besar margin pemasaran efisien sebaliknya semakin kecil margin pemasaran biasanya saluran pemasaran semakin efisien. Dari sisi margin pemasaran saluran 3 merupakan saluran pemasaran kakao yang paling efisien karena memiliki margin pemasaran paling kecil dibandingkan saluran 1 dan saluran 2 .

biasanya saluran pemasaran semakin kurang

Share Net Margin Lembaga Pemasaran Kakao

Tabel V-8. Net Share Margin Lembaga Pemasaran Pada 3 Saluran Pemasaran Kakao Di Kecamatan Ranto Peureulak, 2016

\begin{tabular}{|c|c|c|c|c|c|}
\hline \multirow[b]{2}{*}{ Saluran } & \multirow[b]{2}{*}{ Lembaga Pemasaran } & $\begin{array}{c}\text { Harga } \\
\text { Beli }\end{array}$ & $\begin{array}{c}\text { Harga } \\
\text { Jual }\end{array}$ & Biaya & Net Margin \\
\hline & & $(\mathrm{Rp} / \mathrm{Kg})$ & (Rp/Kg) & (Rp/Kg) & (Rp/Kg) \\
\hline \multirow{4}{*}{1} & Pedagang Desa & 20.000 & 22.000 & 550 & 1.450 \\
\hline & Pedagang Kecamatan & 22.000 & 24.000 & 775 & 1.225 \\
\hline & Pedagang Kabupaten & 24.000 & 26.000 & 850 & 1.150 \\
\hline & Pedagang Propinsi & 26.000 & 28.500 & 1.350 & 1.150 \\
\hline \multirow{4}{*}{2} & Pedagang Desa & 21.000 & 23.000 & 550 & 1.450 \\
\hline & Pedagang Kecamatan & - & - & - & - \\
\hline & Pedagang Kabupaten & 23.000 & 26.000 & 950 & 2.050 \\
\hline & Pedagang Propinsi & 26.000 & 29.000 & 1.350 & 1.650 \\
\hline \multirow{4}{*}{3} & Pedagang Desa & - & - & - & - \\
\hline & Pedagang Kecamatan & - & - & - & - \\
\hline & Pedagang Kabupaten & 23.500 & 26.000 & 1.050 & 1.450 \\
\hline & Pedagang Propinsi & 26.000 & 29.000 & 1.350 & 1.650 \\
\hline
\end{tabular}

Sumber: Data Primer diolah

Tabel V-8 menjelaskan bahwa penerima keuntungan bersih (net margin) pada saluran 1 adalah pedagang desa yaitu sebesar Rp. $1.450 / \mathrm{Kg}$, pada saluran 2 penerima keuntungan bersih terbesar adalah pedagang kabupaten

yaitu sebesar Rp. $2.050 / \mathrm{Kg}$ dan saluran 3 penerima keuntungan bersih tertinggi yaitu pedagang propinsi yaitu sebesar Rp. 1.650/Kg kakao. 

pemasaran dapat dilihat pada tabel berikut.

Tabel V-9. Farmer Share Pada 3 Saluran Pemasaran Kakao Di Kecamatan Ranto Peureulak, 2016

\begin{tabular}{|l|l|l|ll|l|}
\hline No & $\begin{array}{l}\text { Saluran } \\
\text { Pemasaran }\end{array}$ & $\begin{array}{l}\text { Harga Petani } \\
(\mathrm{Rp} / \mathrm{Kg})\end{array}$ & $\begin{array}{l}\text { Harga Pedagang Propinsi } \\
(\mathrm{Rp} / \mathrm{Kg})\end{array}$ & $\begin{array}{l}\text { Farmer Share } \\
(\%)\end{array}$ & \\
\hline 1 & 1 & 20.000 & 28.500 & 70,18 \\
2 & 2 & 21.000 & 29.000 & 72,41 \\
3 & 3 & 23.500 & 29.000 & 81,03 & \\
\hline \multicolumn{2}{l}{ Rata-Rata } & & 74,11 & \\
\hline
\end{tabular}

Sumber: Data Primer diolah

Tabel V-9 menjelaskan bahwa Farmer Share pemasaran kakao di Kecamatan Ranto Peureulak rata-rata sebesar $74,11 \%$. Farmer Share pemasaran pada saluran 1 sebesar 70,18 \% dan saluran 2 sebesar $72,41 \%$ sedangkan Farmer Share pemasaran saluran 3 sebesar 81,03 \%. Dari sisi Farmer Share pemasaran saluran 3 merupakan saluran pemasaran kakao yang paling efisien karena memiliki Farmer Share pemasaran paling besar dibandingkan saluran 1 dan saluran 2. Semakin besar harga yang diterima petani kakao maka pemasaran kakao dapat dikatakan semakin efisien dan Tabel V-10. Efisien Pada 3 Saluran Pemasaran Kakao memihak kepada petani. Bagaimanapun petani adalah produsen apabila harga berpihak pada produsen, produsen akan cendrung mempertahankan atau meningkatkan produksinya.

\section{Efisiensi Pemasaran}

Efisiensi pemasaran adalah perbandingan antara total biaya pemasaran dengan harga barang pada tingkat konsumen. Adapun efisiensi pemasaran kakao di Kecamatan Ranto Peureulak pada 3 saluran pemasaran dapat dilihat pada tabel berikut.

\begin{tabular}{|l|l|l|l|}
\hline No & Saluran Pemasaran & Efisiensi (\%) & Kesimpulan \\
\hline 1 & 1 & 12,37 & Efisien $(<50 \%)$ \\
2 & 2 & 9,83 & Efisien $(<50 \%)$ \\
3 & 3 & 8,28 & Efisien $(<50 \%)$ \\
\hline \multicolumn{2}{|l|}{ Rata-Rata } & 10,40 & \\
\hline
\end{tabular}

Sumber: Data Primer diolah

Tabel V-10 menjelaskan bahwa efisiensi pemasaran kakao di Kecamatan Ranto Peureulak rata-rata sebesar 10,40 \% (Efisien karena $<50 \%)$. Efisiensi pemasaran pada saluran 1 sebesar $12,37 \%$ dan saluran 2 sebesar 9,83\% sedangkan efisien pemasaran saluran 3 sebesar 8,28 \%. Semakin besar efisiensi pemasaran biasanya saluran pemasaran semakin kurang efisien suatu saluran pemasaran sebaliknya semakin kecil efisiensi pemasaran biasanya saluran pemasaran semakin efisien. Dari sisi efisiensi pemasaran saluran 3 merupakan saluran pemasaran kakao yang paling efisien

karena memiliki efisiensi pemasaran paling kecil dibandingkan saluran 1 dan saluran 2. Kecilnya nilai efisiensi pemasaran pada salura 3 dikarenakan karena rantai pemasaran kakao sangat pendek sehingga tidak banyak biaya pemasaran yang tercipta yang pada akhirnya harga yang diterima petani kakao sebagai produsen semakin tinggi.

\section{KESIMPULAN DAN SARAN}

Efisiensi pemasaran kakao di Kecamatan Ranto Peureulak rata-rata sebesar 10,40 \% (Efisien karena $<50 \%$ ). Efisiensi pemasaran pada 
saluran 1 sebesar 12,37\% dan saluran 2 sebesar 9,83\% sedangkan efisien pemasaran saluran 3 sebesar 8,28 \%. Dari sisi efisiensi pemasaran saluran 3 merupakan saluran pemasaran kakao yang paling efisien karena memiliki efisiensi pemasaran paling kecil dibandingkan saluran 1 dan saluran 2.

\section{Saran}

1. Sudah waktunya petani kakao di Kecamatan Ranto Peureulak memanfaatkan informasi tentang pemasaran farmer baik itu mengenai harga dan permintaan sehingga bisa memproduksi sesuai tingkat harga yang diharapkan.

2. Untuk pedagang pengumpul hendaknya mempertimbangkan harga jual kakao agar petani memperoleh keuntungan yang layak sehingga petani tetap mempertahankan usahatani kakao.

\section{DAFTAR PUSTAKA}

Alham, Fiddini. 2013. Analisis Pemasaran Garam di Kabupaten Sumenep Jawa Timur. Tesis Tidak Dipublikasikan. IPB. Bogor.

Anonymous, 2016. Potensi Wilayah BPPPK Kecamatan Ranto Peureulak Tahun 2016. Ranto Peureulak. Aceh Timur

Daniel, M., 2002. Pengantar Ekonomi Pertanian. Bumi Aksara, Jakarta.

Ditjen Perkebunan, 2009. Sosialisasi Gerakan Peningkatan Produksi dan Mutu Kakao Nasional. Diambil http:/www.deptan.go.id/kioskplus /detailarsip.php

Gitosudarmo, I. 2001, Manajemen Pemasaran, BPFE, Yokyakarta.

Kottler, 2001. Manajemen Pemasaran : Analisis Perencanaan, Implementasi dan Pengendalian. PT. Prehallindo. Jakarta.

Limbong dan Sitorus, 2005. Pengantar Tataniaga Pertanian. Jurusan IImu-ilmu
Sosial Ekonomi Pertanian. Fakultas Pertanian IPB. Bogor.

Mangdeska, 2009. Analisis pendapatan usahatani kakao (Theobroma cacao,L) dan Faktor-faktor yang mempengaruhinya di Nagari Lubuak Batingkok Kecamatan Harau Kabupaten Lima Puluh Kota, diambil dari http://www.indowebster.com/analisis pendapatan petani kakao.html

Mubyarto. 2002. Pengantar Ekonomi Pertanian. Edisi Keenam. LP3S. Jakarta.

Nazir, M, 2005, Metode Penelitian, Ghalia Indonesia, Jakarta.

Rahim. A dan Hastuti D. 2007. Pengantar Teori dan Kasus Ekonomi Pertanian. Penebar Swadaya. Jakarta.

Rini. 2005. Pengantar Sosisologi Pertanian. Edisi Keenam. LP3S. Jakarta.

Soekartawi., 2002. Prinsip Dasar Manajemen Pemasaran Hasil-hasil Pertanian. Raja Grafindo Persada, Jakarta.

Sugiyono, 2007. Metode Penelitian Bisnis dan Aplikasi. Alfabeta, Bandung.

Sunanto, H. 2004. Cokelat : Pengolahan Hasil dan Aspek Ekonominya. UGM. Yogyakarta

Wahyudi, T., \& P. Raharjo. 2008. Sejarah dan Prospek. Dalam: T. Wahyudi, T.R. Pangabean \& Pujianto (eds.). Panduan Lengkap Kakao Manejemen Agribisnis dari Hulu hingga Hilir. Penebar Swadaya. Jakarta. hal: 11-26. 